\title{
Spatial attention modulates feature crosstalk in visual word processing
}

\author{
EVAN F. RISKo \\ University of British Columbia, Vancouver, British Columbia, Canada \\ AND \\ Jennifer A. Stolz And Derek Besner \\ University of Waterloo, Waterloo, Ontario, Canada
}

\begin{abstract}
One major idea about spatial attention is that it serves to modulate crosstalk between features during reading. Two reading aloud experiments are reported in which a cue-validity manipulation was combined with manipulations that are thought to increase the likelihood of feature-level crosstalk: interletter spacing and the presence or absence of irrelevant features. Both experiments yielded an interaction between the effects of spatial cuing and each of these factors. These results are taken to support the hypothesis that when spatial attention is focused on the word, it provides protection against crosstalk among features in the context of reading aloud.
\end{abstract}

The role of spatial attention in visual word processing has long concerned researchers. This research has focused predominately on questions concerning selective attention (e.g., the debate over early vs. late selection; e.g., Brown, Gore, \& Carr, 2002; Risko, Stolz, \& Besner, 2005), for which words functioned as convenient stimuli (see Lachter, Forster, \& Ruthruff, 2004, for a review). In contrast, questions regarding how attention influences $v i$ sual word processing have received much less consideration. It is to these questions that we turned in the present investigation.

\section{Spatial Attention}

Visual spatial attention allows individuals to select specific regions of the visual field for preferential processing (see Carrasco, 2006; Posner \& Peterson, 1990, for reviews). The present investigation was concerned with covert spatial attention (i.e., shifts of spatial attention without eye movements). Attending to a location where a target appears has been demonstrated to improve performance across a number of different tasks (see, e.g., Carrasco, 2006).

The most popular way to measure the influence of spatial attention is in the context of the spatial cuing paradigm (Posner, 1980). In this paradigm, a target is preceded by a spatial cue indicating the upcoming target's location (i.e., a valid trial) or a nontarget location (i.e., an invalid trial). Response times are typically faster on valid than on invalid trials (Posner, 1980). This cuing effect can be taken as an index of the influence of spatial attention on performance. For example, if spatial attention has no influence on processing, then no cuing effect should be observed.
To understand the role of spatial attention in visual word processing, previous research has combined the cue validity manipulation with different word-processing tasks (Besner, Risko, \& Sklair, 2005; Ducrot \& Grainger, 2007; Hardyck, Chiarello, Dronkers, \& Simpson, 1985; Lindell \& Nicholls, 2003; McCann, Folk, \& Johnston, 1992; Nicholls \& Wood, 1998; Nicholls, Wood, \& Hayes, 2001; Ortells, Tudela, Noguera, \& Abad, 1998; Stolz \& McCann, 2001; Stolz \& Stevanovski, 2004). For example, McCann et al. combined a spatial cuing manipulation with a lexical decision task. McCann et al. (and others subsequently; Lindell, \& Nicholls, 2003; Nicholls \& Wood, 1998; Nicholls et al., 2001; Ortells et al., 1998; Stolz \& McCann, 2000; Stolz \& Stevanovski, 2004) demonstrated a robust cuing effect in lexical decision, suggesting that spatial attention influences word processing in some manner. Nicholls and Wood (1998) and Nicholls et al. also demonstrated a robust cuing effect in a reading aloud task. To better understand the nature of this cuing effect, the cue validity manipulation has been combined with manipulations that influence particular subcomponents of word processing. The nature of the joint effects of these factors can then be used to infer which reading processes are influenced by spatial attention (see, e.g., Sternberg, 1969).

McCann et al. (1992) combined a manipulation of cue validity with manipulations of word frequency and lexicality in the context of a lexical decision task. The effects of cue validity were additive with both of these factors. Specifically, the size of the cuing effect was equivalent for high- and low-frequency words and equivalent for words and nonwords. Nicholls and Wood (1998), Nicholls et al.

E. F. Risko, efrisko@psych.ubc.ca 
(2001), and Ortells et al. (1998) reported similar results. These results suggest that cue validity does not influence the same process as do word frequency and lexicality, which are widely taken as having their effects at a lexical level (McCann et al., 1992). McCann et al.'s results thus suggest that spatial attention does not influence lexicallevel processing. McCann et al. suggested instead that spatial attention likely affects visual word processing at a prelexical level (e.g., feature and/or letter level). In the present investigation, we sought more direct evidence for such a prelexical locus for spatial attention. Specifically, we tested the idea that spatial attention influences crosstalk among features (Brown et al., 2002; Brown, RoosGilbert, \& Carr, 1995).

\section{Feature-Level Crosstalk}

Brown and colleagues (Brown et al., 2002; Brown et al., 1995) have argued that spatial attention influences early feature-level crosstalk. Their evidence for this claim was derived from their work on spatial attention's influence on Stroop dilution. Briefly, Stroop dilution refers to the observation that the presence of another stimulus dilutes the magnitude of the Stroop effect. Brown and colleagues (Brown et al., 2002; Brown et al., 1995) have argued that Stroop dilution arises from crosstalk between the features of the stimuli that are in the display (i.e., the color word and the other stimulus). Crosstalk among features leads to degraded representations being fed forward to the word recognition system, resulting in reduced activation of the words. This reduced activation results in the diluted effect of the color word on color-identification processes.

Brown et al. (2002) argued that spatial attention modulates this early feature-level crosstalk, demonstrating that spatially cuing the location of the irrelevant color word eliminated Stroop dilution. If the irrelevant color word was presented at an attended location, the presence of another wordlike stimulus no longer reduced the Stroop effect. Brown et al. (2002) thus argued that spatial attention "protected" the color word from crosstalk with features from another stimulus.

The idea that spatial attention protects a word from crosstalk with features from another stimulus cannot explain the cuing effects observed in single-word displays, because in a single-word display there is no other stimulus to contribute additional features; thus, there would be no benefit of spatial attention's protection. Despite this, there is clear evidence for an effect of spatial attention in single-word displays (Lindell \& Nicholls, 2003; McCann et al., 1992; Nicholls \& Wood, 1998; Nicholls et al., 2001; Ortells et al., 1998; Stolz \& McCann, 2000; Stolz $\&$ Stevanovski, 2004). This limitation of the crosstalk idea can be addressed, however, if we extend spatial attention's role to the modulation of crosstalk among features within words. For example, spatial attention may limit the amount of crosstalk between different features and/or letters of a word (see, e.g., Besner \& Stolz, 1999). This could occur if spatial attention influenced the fidelity with which the locations of individual features were encoded (see, e.g., Ashby, Prinzmetal, Ivry, \& Maddox, 1996). For example, Ashby et al. have argued that spatial attention influences noise in the encoding of feature location. Adding noise to the encoding of feature location would increase the likelihood that a particular letter feature would interfere with the identification of other letters in the string (i.e., featurelevel crosstalk). Ashby et al. used this idea to explain spatial attention's role in modulating illusory conjunction or feature-integration errors. In a similar vein, in Wolford's (1975) feature perturbation theory, letter identification can be impaired by letter features from adjacent letters migrating to the wrong letter location.

To test the idea that spatial attention modulates crosstalk among features within a word, we combined a manipulation of spatial attention (i.e., cue validity) with factors that would increase the likelihood of feature-level crosstalk. If presenting a word at an unattended location increases the likelihood of crosstalk among features, then the effect of cuing on reading aloud should be larger when there is greater opportunity for feature-level crosstalk.

\section{EXPERIMENTS 1A AND 1B}

In Experiments 1A and 1B, the opportunity for crosstalk among features was increased by reducing interletter spacing. Reducing interletter spacing (crowding) is known to impair both letter identification (see, e.g., Bouma, 1970; Wolford, 1975; Wolford \& Chambers, 1983) and word reading (Chung, 2002; Yu, Cheung, Legge, \& Chung, 2007; see Levi, 2008, for a recent review). Here, reducing interletter spacing was hypothesized to increase the likelihood of feature-level crosstalk (see, e.g., Ashby et al., 1996; Wolford, 1975; Wolford \& Chambers, 1983). For example, in the context of Ashby et al.'s locational uncertainty model of feature integration, features are integrated (i.e., bound together) via their proximity to each other. By reducing the distance between two letters within a word, therefore, the potential for integration errors (e.g., illusory conjunctions between features of adjacent letters) is increased (see also Wolford, 1975).

The interletter-spacing manipulation was combined with a manipulation of cue validity. Words were presented above or below a central fixation. This use of vertical presentation was based on previous work that used the spatial cuing paradigm in combination with word-processing tasks (McCann et al., 1992; Stolz \& McCann, 2000; Stolz $\&$ Stevanovski, 2004). Work using a horizontal presentation has yielded qualitatively similar results (Ducrot \& Grainger, 2007; Lindell \& Nicholls, 2003; Nicholls \& Wood, 1998; Nicholls et al., 2001). The word was preceded by an abrupt onset spatial cue that appeared briefly either above or below fixation. The cue appeared either in the upcoming target location (i.e., a valid cue) or opposite that location (i.e., an invalid cue). The cue was assumed to capture spatial attention; thus, the difference in reading performance between the valid and invalid trials (i.e., the cuing effect) can be used as an index of the influence of spatial attention on reading. Valid and invalid cues were equally likely (i.e., the cue was uninformative with respect to the target location); thus, the cue validity manipulation used in the present investigation can be considered a manipulation of exogenous spatial attention. 
The spatial cuing paradigm was combined with a standard reading aloud task. Previous studies combining spatial cuing with a word-processing task have used a mix of lexical decision and reading aloud tasks, though the former have been more popular. Critically, the results have been consistent across both paradigms to date. Reading aloud was chosen for the present investigation in order to facilitate future integration of research on spatial attention in word processing and current computational modeling efforts that have focused on reading aloud (see, e.g., Coltheart, Rastle, Perry, Langdon, \& Ziegler, 2001; Perry, Ziegler, \& Zorzi, 2007). The use of reading aloud also focused the investigation on intentional word processing rather than on unintentional word processing, which is typically studied in filtering tasks such as Stroop (see, e.g., Brown, 1996). The different demands placed on the word-processing system across these two different contexts may place different demands on spatial attention (Brown, 1996; Brown et al., 2002). We were interested here in the role of spatial attention when the task was word processing specifically.

If spatial attention modulates the amount of crosstalk among features during intentional word processing, then the cuing effect should be larger when the opportunity for feature-level crosstalk is higher; thus, in Experiments 1A and $1 \mathrm{~B}$, which combined a cue validity manipulation with an interletter-spacing manipulation, the cuing effect on reading aloud (invalid - valid) should be larger when interletter spacing was reduced. Experiments $1 \mathrm{~A}$ and $1 \mathrm{~B}$ were identical except that different stimulus sets were used, permitting an opportunity to assess the replicability and generalizability (across different items) of the reported results.

\section{Method}

Participants. Thirty-two (16 each in Experiment 1A and Experiment 1B) English-speaking undergraduates from the University of Waterloo were paid $\$ 4$ each or received course credit to participate.

Apparatus. Stimulus presentation was controlled using a Pentium IV 2.0-GHz computer running E-Prime 1.1 software. Vocal responses were collected using a Plantronics LS1 microphone headset and a voice key assembly. Stimuli were displayed on a 17-in. ADI Microscan monitor.

Design. A 2 (cue validity: valid vs. invalid) $\times 2$ (interletter spacing: normal vs. reduced) within-subjects design was used. On half of the trials, the target word was presented with normal interletter spacing, and on the other half of the trials, the target word was presented with interletter spacing reduced.

Stimuli. A silver (RGB 162, 162, 162) fixation symbol (+) was presented at the center of the screen. Words were presented $1.2 \mathrm{~cm}$ (approximately $1.3^{\circ}$ of visual angle) above or below the fixation and were preceded by an abrupt onset cue that consisted of a white (RGB 255, 255, 255) rectangle presented $2.5 \mathrm{~cm}$ above or below fixation (approximately $2.7^{\circ}$ ). Words were always presented in white, lowercase, 12-point Courier New font.

In Experiment 1A, the word list consisted of 168 four-letter, monosyllabic words. The average frequency was 46 occurrences per million, and each item had nine neighbors on average (Davis, 2005). In the normal spacing condition, letters were separated by 12 pixels horizontally center to center. In the crowded condition, letters were separated by eight pixels horizontally center to center. The normally spaced words measured approximately $2 \mathrm{~cm}$ horizontally (approximately $2.2^{\circ}$ ), and the words with reduced interletter spac- ing measured approximately $1.5 \mathrm{~cm}$ horizontally (approximately $\left.1.7^{\circ}\right)$. Both the normally spaced words and the words with reduced interletter spacing measured approximately $0.5 \mathrm{~cm}$ vertically (approximately $0.5^{\circ}$ ).

In Experiment 1B, the word set consisted of 104 five-letter words. The words were all monosyllabic. The average frequency was 101 occurrences per million, and each item had four neighbors on average (Davis, 2005). The normally spaced words measured $2.4 \mathrm{~cm}$ horizontally (approximately $2.6^{\circ}$ ), and the words with reduced interletter spacing measured $1.8 \mathrm{~cm}$ horizontally (approximately $1.9^{\circ}$ ). In both Experiment 1A and Experiment 1B, all items were rotated through all conditions across participants.

Procedure. Participants were tested individually and were seated approximately $53 \mathrm{~cm}$ from the screen. Participants were instructed to read aloud the presented word while remaining fixated on the $(+)$ symbol. Each trial began with a fixation symbol that was presented for $750 \mathrm{msec}$. The spatial cue was then presented for $50 \mathrm{msec}$ The word appeared $100 \mathrm{msec}$ after the offset of the spatial cue (i.e., $\mathrm{SOA}=150 \mathrm{msec}$ ) and stayed on the screen until the participant responded (see Figure 1 for an example trial). After the participant made her/his response, the experimenter recorded accuracy as well as any spoiled trials (e.g., voice key failures). In Experiment 1A, there were 8 practice trials and 160 experimental trials, and in Experiment $1 \mathrm{~B}$, there were 8 practice trials and 96 experimental trials.

\section{Results}

Spoiled trials (i.e., trials in which the voice key was unintentionally tripped - by a cough, for example; Experiment 1A, 2.4\%; Experiment 1B, 4.4\%) were removed prior to analysis. Response time (RT) analysis was conducted on trials in which the response was correct. These data were subjected to a recursive trimming procedure that removed outliers on the basis of a criterion cutoff set independently for each participant in each condition by reference to the sample size in that condition (Van Selst \& Jolicœur, 1994). This trimming procedure resulted in the removal of $1.1 \%$ of the RT data in Experiment $1 \mathrm{~A}$ and $1.4 \%$ of the RT data in Experiment 1B. Mean RTs and percentage errors as a function of interletter spacing and cue validity are presented in Figure 2 (Experiment 1A) and Figure 3 (Experiment 1B). A 2 (cue validity: valid vs. invalid) $\times$ 2 (interletter spacing: normal vs. reduced) ANOVA was performed on mean RT and percentage error data.

Experiment 1A. For RTs, the main effects of cue validity $\left[F(1,15)=47.22, M S_{\mathrm{e}}=1,568.45, p<.05\right]$ and of interletter spacing $\left[F(1,15)=18.16, M S_{\mathrm{e}}=234.47\right.$,

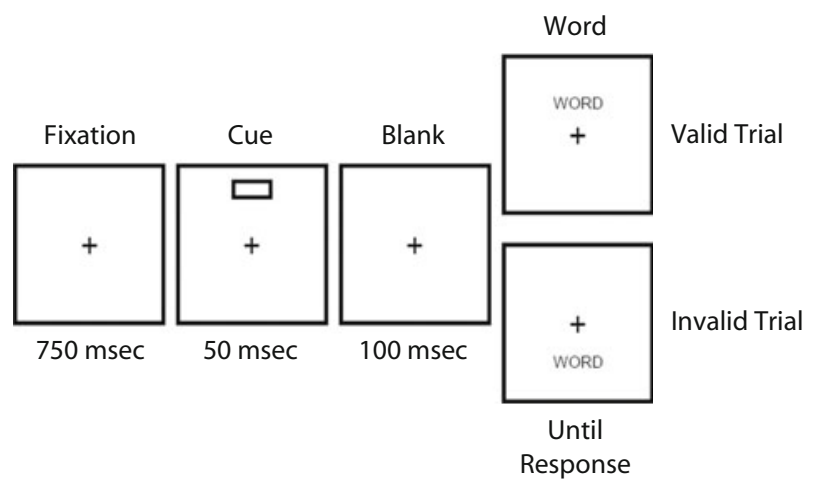

Figure 1. Example trial sequence. 


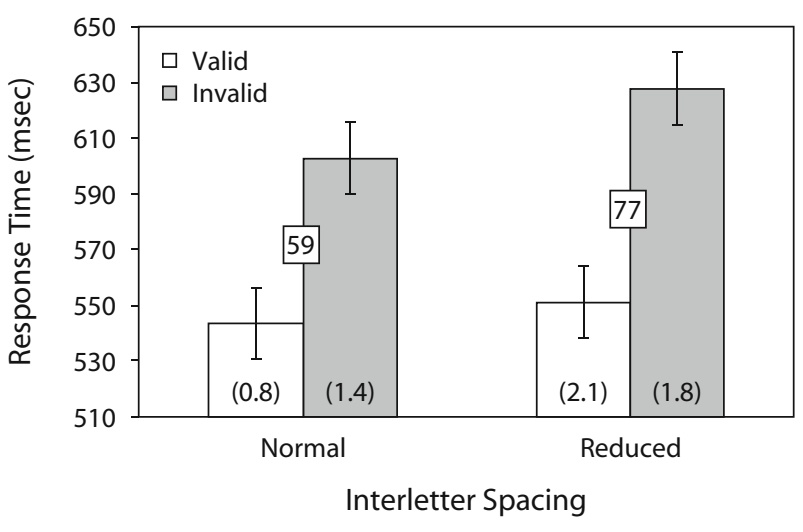

Figure 2. Mean response times (in milliseconds) with $\mathbf{9 5 \%}$ confidence intervals (Masson \& Loftus, 2003) and percentages of error (in parentheses) as a function of cue validity and interletter spacing in Experiment 1A. Cuing effects in milliseconds (invalid - valid) are presented in boxes.

$p<.05]$ were significant. Participants responded faster on valid trials $(547 \mathrm{msec})$ than on invalid trials $(615 \mathrm{msec})$ and faster on normally spaced trials $(573 \mathrm{msec})$ than on reduced-space trials $(589 \mathrm{msec})$. Critically, there was an interaction between the effects of cue validity and interletter spacing $\left[F(1,15)=5.50, M S_{\mathrm{e}}=219.34, p<.05\right]$. The cuing effect (invalid - valid) on normally spaced trials $(59 \mathrm{msec})$ was smaller than the cuing effect on reducedspace trials $(77 \mathrm{msec})$.

In errors there was a marginal effect of spacing $\left[F(1,15)=3.29, M S_{\mathrm{e}}=3.34, p=.08\right]$, in such a way that participants made fewer errors on normally spaced trials $(1.1 \%)$ than on reduced-space trials $(2.0 \%)$. No other effects were significant (all $F_{\mathrm{S}}<2.3$ ).

Experiment 1B. For RTs, the main effects of cue validity $\left[F(1,15)=49.33, M S_{\mathrm{e}}=1,469.50, p<.05\right]$ and of interletter spacing $\left[F(1,15)=12.38, M S_{\mathrm{e}}=806.25\right.$, $p<.05]$ were significant. Participants responded faster on valid trials $(574 \mathrm{msec})$ than on invalid trials $(641 \mathrm{msec})$ and faster on normally spaced trials $(595 \mathrm{msec})$ than on reduced-space trials $(620 \mathrm{msec})$. Critically, there was an interaction between the effects of cue validity and interletter spacing $\left[F(1,31)=8.76, M S_{\mathrm{e}}=393.67, p<.05\right]$. The cuing effect (invalid - valid) on normally spaced trials $(53 \mathrm{msec})$ was smaller than the cuing effect on reducedspaced trials $(82 \mathrm{msec})$. No effects were significant in the error analysis (all $F \mathrm{~s}<2.3$ ).

\section{Discussion}

There was an interaction between the effects of cue validity and interletter spacing in which the cuing effect was larger when interletter spacing was reduced. The consistency across Experiments 1A and 1B also demonstrates that this pattern is replicable and generalizable across two different stimulus sets. The results of Experiments 1A and $1 \mathrm{~B}$ are consistent with the idea that an invalid cue increases the crosstalk among features in a word (see Ashby et al., 1996). When the opportunity for feature-level crosstalk is increased (i.e., through reducing interletter spacing), the magnitude of spatial attention's influence on reading aloud (i.e., the cuing effect) also increases. The increase in feature-level crosstalk when the word is unattended is hypothesized to reflect an increase in noise in the encoding of feature location. Specifically, the encoding of feature location is noisier on invalid trials (i.e., when the word appears at the unattended location) than on valid trials (i.e., when the word appears at the attended location). This increase in noise will increase the amount of crosstalk between features of different letters within the string, resulting in, for example, an increase in integration errors (e.g., Ashby et al., 1996; Wolford, 1975). These integration errors will impair the identification of letters in the string. Experiments 2A and 2B provided converging evidence for the idea that spatial attention influences feature-level crosstalk using a different manipulation.

\section{EXPERIMENTS 2A AND 2B}

In Experiments 2A and 2B, the opportunity for crosstalk among features within a word was increased by adding irrelevant features to the spaces between each letter (e.g., "F/O/R $\backslash T$ "). Backward and forward slashes were used because they constitute plausible letter features. Reading aloud in this condition was compared with a condition in which no irrelevant features were present. The presence of irrelevant features was hypothesized to increase the opportunity for crosstalk in a fashion similar to reducing interletter spacing. Specifically, the irrelevant features could migrate to adjacent letter groups, leading to integration errors. For example, if an irrelevant feature is perceived as part of a letter, this would impair letter identification. If the role of spatial attention in reading is to modulate crosstalk among features, then the presence of irrelevant features should increase the magnitude of the cuing effect. As in Experiments $1 \mathrm{~A}$ and $1 \mathrm{~B}$, Experiments $2 \mathrm{~A}$ and $2 \mathrm{~B}$ were identical except that different stimulus sets were used, permitting an opportunity to assess the replicability and generalizability (across different items) of the reported results.

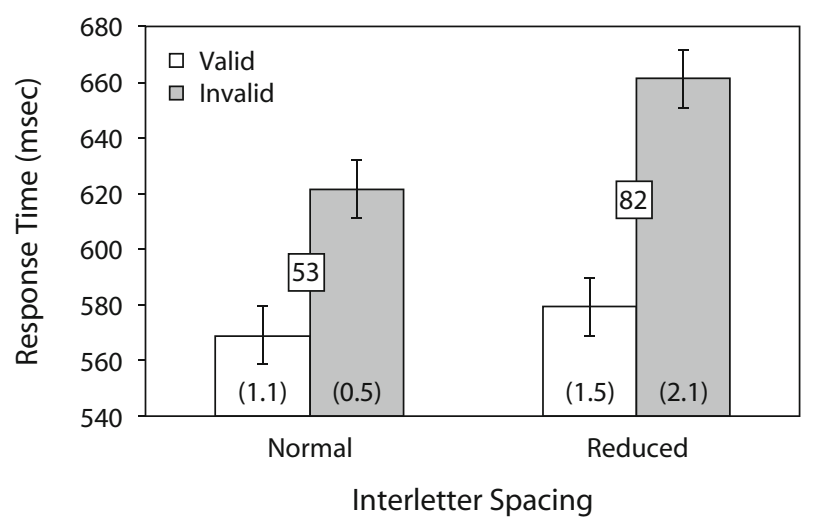

Figure 3. Mean response times (in milliseconds) with $95 \%$ confidence intervals (Masson \& Loftus, 2003) and percentage error (in parentheses) as a function of cue validity and interletter spacing in Experiment 1B. Cuing effects in milliseconds (invalid valid) are presented in boxes. 


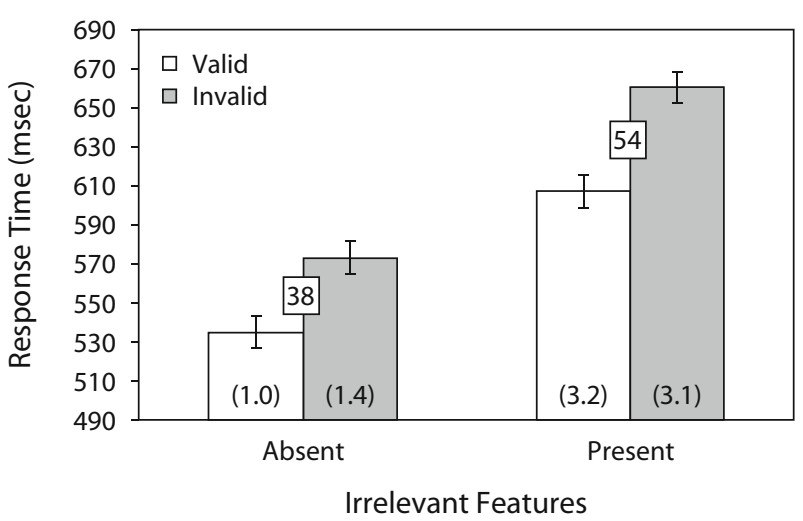

Figure 4. Mean response times (in milliseconds) with $\mathbf{9 5 \%}$ confidence intervals (Masson \& Loftus, 2003) and percentages of error (in parentheses) as a function of cue validity and the presence or absence of irrelevant features in Experiment 2A. Cuing effects in milliseconds (invalid - valid) are presented in boxes.

\section{Method}

Participants. Seventy (48 in Experiment 2A, 32 in Experiment 2B) English-speaking undergraduates from the University of Waterloo were paid $\$ 4$ each or received course credit to participate.

Apparatus. The apparatus was identical to that used in Experiments $1 \mathrm{~A}$ and $1 \mathrm{~B}$.

Design. A 2 (cue validity: valid vs. invalid) $\times 2$ (irrelevant features: present vs. absent) within-subjects design was used. On half of the trials the target word was printed normally (e.g., "FORT"), and on the other half of the trials, the target word was printed with forward and backward slashes interspersed between the letters (e.g. " $F / O \backslash R \backslash T$ ").

Stimuli. In Experiment 2A, the word list from Experiment 1A was used, and in Experiment 2B, the word list from Experiment $1 \mathrm{~B}$ was used. When irrelevant features were present, a horizontal or vertical slash was placed in each space between letters. The forward and backward slashes were in the same font as the letters, and whether a given slash was forward or backward was determined randomly for each space within each word. When the irrelevant features were absent, spaces were introduced between the letters to equate the horizontal extent of the words across conditions. Words were presented in uppercase, 12-point Arial font. In Experiment 2A, words measured approximately $2.2 \mathrm{~cm}$ horizontally (approximately $2.4^{\circ}$ of visual angle) and $0.7 \mathrm{~cm}$ vertically (approximately $0.8^{\circ}$ ). In Experiment $2 \mathrm{~B}$, words measured approximately $2.7 \mathrm{~cm}$ horizontally (approximately $2.9^{\circ}$ ) and $0.7 \mathrm{~cm}$ vertically (approximately $0.8^{\circ}$ ). In both Experiment 2A and Experiment 2B, all items were rotated through all conditions across participants.

Procedure. The procedure was identical to that used in Experiments $1 \mathrm{~A}$ and $1 \mathrm{~B}$.

\section{Results}

Spoiled trials (Experiment 2A, 2.7\%; Experiment 2B, $2.8 \%$ ) were removed prior to analysis. The outlier procedure led to the removal of $1.9 \%$ of the RT data from Experiment $2 \mathrm{~A}$ and $1.6 \%$ of the RT data from Experiment 2B. $\mathrm{RT}$ and percentage error means for each condition are presented in Figure 4 (Experiment 2A) and Figure 5 (Experiment $2 B$ ). A 2 (cue validity: valid vs. invalid) $\times 2$ (irrelevant features: present vs. absent) ANOVA was performed on mean RT and percentage error data.

In Experiment 2A, the main effects for RTs of cue validity $\left[F(1,47)=95.55, M S_{\mathrm{e}}=1,059.60, p<.05\right]$ and of the presence or absence of irrelevant features $[F(1,47)=332.90$,
$\left.M S_{\mathrm{e}}=926.88, p<.05\right]$ were significant. Participants responded faster on valid trials $(571 \mathrm{msec})$ than on invalid trials $(617 \mathrm{msec})$ and faster when irrelevant features were absent $(554 \mathrm{msec})$ than when they were present $(634 \mathrm{msec})$. Critically, there was an interaction between the effects of cue validity and the presence or absence of irrelevant features $\left[F(1,47)=7.51, M S_{\mathrm{e}}=393.09, p<.05\right]$. The cuing effect was smaller when irrelevant features were absent $(38 \mathrm{msec})$ than when irrelevant features were present $(54 \mathrm{msec})$.

For errors, the main effect of the presence or absence of irrelevant features was significant $[F(1,47)=20.89$, $\left.M S_{\mathrm{e}}=8.67, p<.05\right]$, in such a way that participants made fewer errors when irrelevant features were absent $(1.2 \%)$ than when they were present (3.1\%). No other effects were significant (all $F_{\mathrm{S}}<1$ ).

In Experiment 2B, the main effects for RT of cue validity $\left[F(1,31)=72.03 M S_{\mathrm{e}}=758.02 p<.05\right]$ and of the presence or absence of irrelevant features $[F(1,31)=$ $\left.142.89, M S_{\mathrm{e}}=1,001.32, p<.05\right]$ were significant. Participants responded faster on valid trials $(539 \mathrm{msec})$ than on invalid trials $(580 \mathrm{msec})$ and faster when irrelevant features were absent $(526 \mathrm{msec})$ than when irrelevant features were present $(593 \mathrm{msec})$. Critically, there was an interaction between the effects of cue validity and the presence or absence of irrelevant features $\left[F(1,31)=11.92, M S_{\mathrm{e}}=\right.$ $355.68, p<.05]$. The cuing effect was smaller when irrelevant features were absent $(30 \mathrm{msec})$ than when irrelevant features were present $(53 \mathrm{msec})$.

For errors, the main effect of the presence or absence of irrelevant features was significant $[F(1,47)=5.54$, $\left.M S_{\mathrm{e}}=12.00, p<.05\right]$, in such a way that participants made fewer errors when irrelevant features were absent $(1.3 \%)$ than when they were present $(2.8 \%)$. No other effects were significant (all $\left.F_{\mathrm{s}}<1\right)$.

\section{Discussion}

There was an interaction between the effects of cue validity and the presence or absence of irrelevant features, in which the cuing effect on reading aloud was larger when

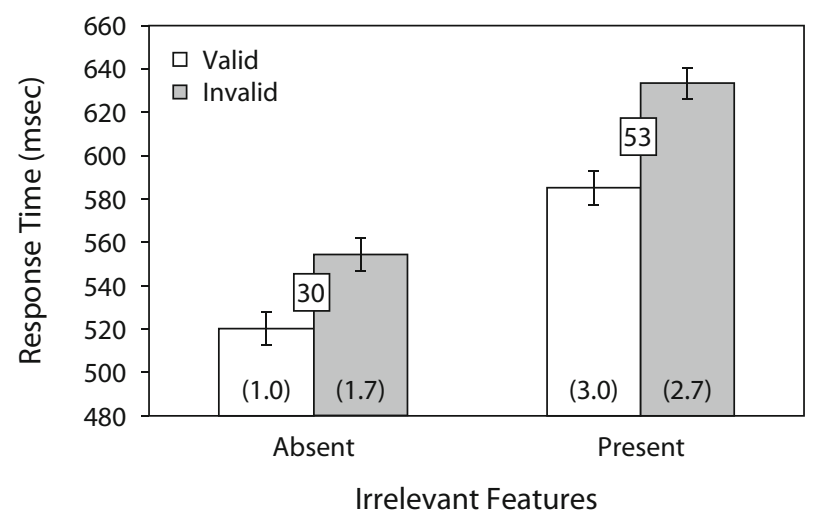

Figure 5. Mean response times (in milliseconds) with $95 \%$ confidence intervals (Masson \& Loftus, 2003) and percentages of error (in parentheses) as a function of cue validity and the presence or absence of irrelevant features in Experiment 2B. Cuing effects in milliseconds (invalid - valid) are presented in boxes. 
irrelevant features were present than when irrelevant features were absent. The consistency across Experiments 2A and $2 \mathrm{~B}$ also demonstrates that this pattern is replicable and generalizable across two different stimulus sets. The results of Experiments 2A and 2B are consistent with the idea, suggested previously, that spatial attention modulates the crosstalk among features within a word (see Ashby et al., 1996). When the opportunity for feature-level crosstalk is increased (i.e., by the presence of irrelevant features), the magnitude of spatial attention's influence on reading aloud (i.e., the cuing effect) also increases.

The results of Experiments 2A and 2B are also important because the addition of irrelevant features, by increasing the amount of stimuli at the target location, should have made it easier to reorient to the word on invalid trials. This is important, because it could be argued that the larger cuing effect in Experiments $1 \mathrm{~A}$ and $1 \mathrm{~B}$ occurred because reducing interletter spacing made it more difficult to reorient to the word on invalid trials (e.g., a "smaller" stimulus might delay reorienting relative to a "larger" stimulus). A similar argument could be applied to Stolz and Stevanovski's (2004) report that the cuing effect was larger for words that were presented in low contrast. A low-contrast stimulus might be more difficult to reorient to on an invalid trial (Snowden, Willey, \& Muir, 2001). The fact that the results from Experiments $2 \mathrm{~A}$ and $2 \mathrm{~B}$ cannot be explained in this way lends support to the idea that spatial attention influences feature-level crosstalk.

The cuing effects in Experiments 2A and 2B differed in magnitude from those in Experiments 1A and 1B. It is unclear why this was the case. The stimulus sets that were used were identical across Experiments $1 \mathrm{~A}$ and $2 \mathrm{~A}$ and across Experiments 1B and 2B. One potential explanation is that the differences resulted from the different fonts that were used. In Experiments $1 \mathrm{~A}$ and 1B, a serif font was used, whereas in Experiments 2A and 2B, a sans serif font was used. The latter font was composed of fewer individual features (if serifs are to be considered features), which might suggest that the differently sized cuing effects reflect differences in featural complexity that would be consistent with the feature-level crosstalk hypothesis suggested here; however, this is only speculation at this point.

Visual field. In Experiments 1A, 1B, 2A, and 2B, words were presented either above or below fixation. Spalek and Hammad (2004) demonstrated that the inhibition of return effect is larger when the cue appears in the upper visual field. They suggested that this might result from a topto-bottom attentional bias. In the present context, such a bias would have produced a smaller cuing effect when the target appeared in the lower visual field. We conducted a reanalysis of the RT data in each experiment, with vertical location of the word as a factor (i.e., above or below fixation). There was a main effect of target location, so that responses were faster for stimuli below fixation in Experiment $2 \mathrm{~A}\left[F(1,47)=6.92, M S_{\mathrm{e}}=556.80, p<.05\right]$ and in Experiment 2B $\left[F(1,31)=11.18, M S_{\mathrm{e}}=1,610.80\right.$, $p<.05]$. Critically, in terms of a top-to-bottom attentional bias, there was a cue validity $\times$ target location interaction, so that the cuing effect was smaller for targets below fixation in both Experiment $2 \mathrm{~A}\left[F(1,47)=11.27, M S_{\mathrm{e}}=\right.$
559.49] and Experiment 2B $\left[F(1,31)=5.54, M S_{\mathrm{e}}=\right.$ $12.00, p<.05]$. This was also true in Experiment 1B $\left[F(1,15)=11.95, M S_{\mathrm{e}}=517.50, p<.05\right]$; however, there was no main effect of visual field in either Experiment 1A or Experiment 1B $(F \mathrm{~S}<1)$. This post hoc analysis is thus generally consistent with a top-to-bottom attentional bias wherein top-to-bottom shifts are faster than bottom-to-top shifts. With respect to the role of spatial attention in word processing, target location did not modulate the critical interactions between cue validity and interletter spacing or between cue validity and the presence or absence of irrelevant features.

\section{GENERAL DISCUSSION}

In the present investigation, a cue validity manipulation was combined with two different manipulations aimed at increasing the likelihood of crosstalk among featuresinterletter spacing and the presence or absence of irrelevant features. Both of these manipulations impaired performance and, more importantly, increased the magnitude of the cuing effect on reading aloud. In addition, both interactions replicated with a different set of items and thus appeared to be robust in the present context. These results are consistent with the idea that spatial attention modulates feature-level crosstalk within words.

\section{Relation to Existing Literature}

The present results join a number of other findings that, taken together, are beginning to yield a clearer picture of the role of spatial attention in word processing. Specifically, spatial attention does not appear to influence lexical-level processing, at least with an exogenous manipulation of spatial attention, but it does influence prelexical levels of processing. The lack of an interaction between the effects of cue validity and word frequency, between cue validity and lexicality, and between cue validity and semantic priming with an exogenous cue (McCann et al., 1992; Nicholls \& Wood, 1998; Nicholls et al., 2001; Ortells et al., 1998; Stolz \& McCann, 2000; Stolz \& Stevanovski, 2004) is consistent with the idea that exogenous spatial attention does not influence lexical levels of processing. In contrast, the demonstration here of an interaction (1) between the effects of cue validity and interletter spacing and (2) between the effects of cue validity and the presence or absence of irrelevant features is consistent with the idea that spatial attention influences prelexical processing. Also consistent with this idea was Stolz and Stevanovski's demonstration that the effects of cue validity interact with those of stimulus contrast in a lexical decision task.

\section{How Does Spatial Attention Influence Word Processing?}

The existing data are consistent with two potentially related mechanisms through which spatial attention influences prelexical processing. First, in the present investigation, evidence has been provided that spatial attention modulates crosstalk between features. When the opportunity for crosstalk between features of a word 
was increased, the effect of cuing on reading that word aloud increased. This increase in feature-level crosstalk when spatial attention was not focused on the word can be considered within Ashby et al.'s (1996) locational uncertainty model of feature integration. In this model, spatial attention is hypothesized to influence the amount of noise in the encoding of feature location. When this noise is increased (e.g., when attention is diverted), the likelihood that two unrelated features (e.g., two features from neighboring letters) will be conjoined increases. These integration errors would slow down correct letter identification and, ultimately, word identification. This proposed mechanism is consistent with a signal-enhancement view of spatial attention and may stem from the fact that removing spatial attention reduces spatial resolution (see, e.g., Yeshurun \& Carrasco, 1999). Also consistent with a signal-enhancement view is the second proposed mechanism through which spatial attention influences prelexical processing. Specifically, Stolz and Stevanovski (2004) demonstrated that the effects of cue validity interacted with those of stimulus contrast in a lexical decision task. They argued that both spatial attention and stimulus contrast influenced the rate of feature uptake (see also Carrasco \& McElree, 2001).

Altogether, therefore, the current evidence is consistent with at least two influences of spatial attention on reading: (1) modulation of feature-level crosstalk, and (2) modulation of the rate of feature uptake. These two prelexical influences of spatial attention on reading are consistent with previous claims about exogenous spatial attention (e.g., Klein, 1994; Prinzmetal, Presti, \& Posner, 1986). For example, Prinzmetal et al. argued that the "spotlight of attention illuminates and helps to integrate features" (p. 367; see also Treisman, 2006; Treisman \& Gelade, 1980). These results are also consistent with a recent suggestion by Finkbeiner and Forster (2008) that spatial attention influences an early pre-domain-specific stage of processing and with numerous demonstrations that drawing spatial attention away from a prime can significantly reduce and in many cases eliminate repetition priming (Besner et al., 2005; Lachter et al., 2004; Marzouki \& Grainger, 2008; Marzouki, Grainger, \& Theeuwes, 2007; Marzouki, Meeter, \& Grainger, 2008). For example, Marzouki et al. (2007) demonstrated that repetition priming in a letter-identification task was eliminated when the prime was unattended, and Besner et al. (2005) showed the same with words. In this sense, the prelexical influence we have postulated would occur before any domain-specific wordprocessing stage is accessed.

Another important issue is the extent to which the hypothesized prelexical influence of spatial attention influences processing downstream in the context of word processing. One idea is that the prelexical influence cascades through the word-processing system, influencing subsequent stages as well. This account would be consistent with the processing dynamics of most existing computational models of reading aloud (Coltheart et al., 2001; Perry et al., 2007). The problem with this account is that it is inconsistent with existing data. Specifically, it predicts that cue validity will also interact with factors that influence, for example, lexical or semantic processing. This prediction has not been supported across a number of experiments (McCann et al., 1992; Nicholls \& Wood, 1998; Nicholls et al., 2001; Ortells et al., 1998; Stolz \& McCann, 2000; Stolz \& Stevanovski, 2004). In general, the assumption that processing is always cascaded and is always engaged in interactive activation has recently been questioned, and it has been argued that processing is rather more dynamic and sensitive to the local context than has been widely envisioned to date (e.g., Borowsky \& Besner, 2006; Ferguson, Robidoux, \& Besner, 2009; O’Malley \& Besner, 2008; O’Malley, Reynolds, \& Besner, 2007). This idea leaves open to investigation the factors that modulate the propagation of early disruptions to higher levels. For example, it might be the case that differences exist between intentional and unintentional reading tasks in the likelihood that an early disruption is propagated forward (see, e.g., Brown, 1996). In the former case, in which the output of the word-processing system is central to task performance (as in reading aloud), early normalization might occur prior to lexical access.

\section{Alternative Accounts}

In the present investigation, we have focused on what we have called feature-level crosstalk. Specifically, we have argued that spatial attention modulates the noise in the encoding of feature location in such a way that when a word is unattended, the likelihood of crosstalk between features increases. It remains possible that letters actually function as "features" and that spatial attention modulates wholeletter localization. For example, letter-position dyslexia, in which letters within a letter string migrate, is thought to be caused by an attentional impairment (Friedmann \& Gvion, 2001). In addition, letter migrations that occur in briefly presented multielement displays have also been associated with spatial attention (Treisman \& Souther, 1986; but see Mozer, 1983).

A related hypothesis is that spatial attention influences the segregation of letters within a word. In Wolford's (1975) feature perturbation theory, before a set of features can be matched to a stored letter representation, feature groups have to be created. This occurs through the extraction of the spaces between letters. Failure to extract a space between adjacent letters leads to the amalgamation of what would be two separate feature groups into a single feature group, thus impairing letter identification. In this case, if an invalid cue disrupts letter segregation, then this disruption would be exacerbated by a reduction in interletter spacing and the inclusion of irrelevant features, because both make the spaces between adjacent letters less conspicuous.

\section{A More Complicated Picture?}

The claim that spatial attention influences only prelexical processing during reading may not be the whole story. Evidence of a more complex relationship between spatial attention and reading comes from studies that used different means to manipulate spatial attention (i.e., other than the spatial cuing procedure discussed here) and from studies that used a horizontal visual-field manipulation. 
In the present work - and in much of the existing work on the relationship between spatial attention and reading an on/off cuing procedure was used in which the letter string was presented either at the attended location (i.e., on) or at a different location (i.e., off). Elsewhere, Auclair and Siéroff (2002) and Siéroff and Posner (1988; see also Ducrot \& Grainger, 2007) used a manipulation of spatial attention within the letter string. They demonstrated that cuing the beginning or end of a letter string had little or no effect on words but had a significant effect on nonwords (i.e., beginning-cued nonwords were identified more accurately than were end-cued nonwords). These results are important, because they provide evidence for an interaction between lexical information and spatial attention that is inconsistent with the results from studies that used an on/off cuing paradigm. Auclair and Siéroff explained this discrepancy by suggesting that the interaction between the effects of cuing and lexicality arises because of a lexical influence on the redistribution of spatial attention within words (see also Brunn \& Farah, 1991). Critically, this interaction would not be detected with a manipulation of spatial attention that does not influence the distribution of attention within the word (i.e., an on/off cuing procedure). According to this account, there may be both betweenword and within-word effects of spatial attention on word processing.

Evidence for multiple roles of spatial attention in word processing has also been suggested by research that used visual hemifield as a factor. Responses to words are faster when presented in the right visual field (RVF) than when presented in the left visual field (LVF). When words are presented laterally, the cuing effect is larger for words presented in the LVF than for words presented in the RVF (Ducrot \& Grainger, 2007; Lindell \& Nicholls, 2003; Nicholls \& Wood, 1998; Nicholls et al., 2001). Ducrot and Grainger interpreted this pattern as reflecting an inherent rightward bias in spatial attention (thus ameliorating the influence of cuing on the right side). Nicholls and Wood explained this effect by suggesting that the right hemisphere processes words in a letter-by-letter fashion that requires the serial application of spatial attention; however, the left hemisphere processes words in a holistic fashion in which whole words rather than letters function as the perceptual units. Spatial attention thus, influences word processing when the word is presented to either the LVF or the RVF, but the need to apply spatial attention in a letter-by-letter fashion may be specific to LVF presentations. This interpretation again suggests the possibility that spatial attention has multiple roles in word processing in addition to an early prelexical effect.

Given how on/off manipulations of spatial attention can influence reading (i.e., feature-level crosstalk, feature uptake), what role might spatial attention play within a word? One idea is that spatial attention is involved in sublexical processing. In this case, spatial attention moves through the letter string as a kind of part-based processing mechanism. For example, in Perry et al.'s (2007) computational model of reading aloud $(\mathrm{CDP}+)$, spatial attention is responsible for graphemic parsing. Graphemic parsing occurs after letter identification and operates from left to right across the letter string. Spatial attention plays a similar role in Ans, Carbonnel, and Valdois's (1998) connectionist multiple-trace memory model of reading. On presentation of the letter string, spatial attention initially encompasses the entire letter string (i.e., global mode). If retrieval of a word fails and a sublexical reading strategy has to be adopted, then spatial attention is focused on constituent parts of the letter string in order to generate a pronunciation (i.e., analytic mode). This idea is certainly intriguing and appears to have some support in the literature. For example, Facoetti et al. (2006) demonstrated that speeded nonword reading - which, arguably, relies heavily on these sublexical mechanisms - was correlated with the magnitude of an individual's spatial cuing effect. The idea that spatial attention can be focused within a word or distributed across a word has also been used as an explanation for the drastic reduction in the magnitude of the Stroop effect when only a single letter is colored or is colored and spatially cued (see Besner, 2001; Besner \& Stolz, 1999; Besner, Stolz, \& Boutilier, 1997).

In this light, spatial attention could be viewed as contributing to the precise and timely encoding of the letter string and also to the later construction of a phonological code via the serial encoding of that letter string. This conclusion is speculative; considerable work remains before a complete understanding of the role(s) of spatial attention in word processing can be achieved.

\section{Exogenous Versus Endogenous Spatial Attention}

The experiments reported here used an exogenous manipulation of spatial attention. Stolz and McCann (2000) and Stolz and Stevanovski (2004) have demonstrated that exogenous and endogenous spatial attention may influence word processing in qualitatively different ways. Specifically, they demonstrated that the effects of cue validity and semantic priming (e.g., "DOCTOR" preceded by "NURSE") had additive effects on RT when the cue was uninformative (i.e., exogenous), but these same factors interacted in an overadditive fashion when the cue was informative (i.e., endogenous). This interaction between cue type (i.e., exogenous vs. endogenous), spatial attention, and word processing may be limited to higher levels of processing within the word-processing architecture (i.e., semantics). For example, Stolz and Stevanovski demonstrated that the effects of cue validity and stimulus quality interacted with both an uninformative (i.e., exogenous) and an informative (i.e., endogenous) cue. Additionally, the additivity between cue validity and word frequency has been demonstrated with both an uninformative (Ortells et al., 1998) and an informative cue (McCann et al., 1992).

\section{Conclusion}

The present investigation has provided two new findings that, in conjunction with previous work, serve to constrain theories regarding the role of spatial attention in visual word processing. In addition, a number of areas in which additional research is required have been identified. Overall, the present investigation represents an important step in understanding the role of spatial attention in visual word processing. 


\section{AUTHOR NOTE}

This work was supported by an NSERC Canada Graduate Scholarship to E.F.R., NSERC Operating Grant 018395 to J.A.S., and NSERC Operating Grant A0998 to D.B. Correspondence concerning this article should be addressed to E. F. Risko, Psychology Department, University of British Columbia, Vancouver, BC V6T 1R9 Canada (e-mail: efrisko@, psych.ubc.ca).

\section{REFERENCES}

Ans, B., Carbonnel, S., \& VAldois, S. (1998). A connectionist multipletrace memory model for polysyllabic word reading. Psychological Review, 105, 678-723. doi:10.1037/0033-295X.105.4.678-723

Ashby, F. G., Prinzmetal, W., Ivry, R., \& Maddox, W. T. (1996). A formal theory of feature binding in object perception. Psychological Review, 103, 165-192. doi:10.1037/0033-295X.103.1.165

Auclair, L., \& SiÉroff, E. (2002). Attentional cuing effect in the identification of words and pseudowords of different length. Quarterly Journal of Experimental Psychology, 55A, 445-463. doi:10.1080/02724980143000415

Besner, D. (2001). The myth of ballistic processing: Evidence from Stroop's paradigm. Psychonomic Bulletin \& Review, 8, 324-330.

Besner, D., Risko, E. F., \& SkLair, N. (2005). Spatial attention as a necessary preliminary to early processes in reading. Canadian Journal of Experimental Psychology, 59, 99-108. doi:10.1037/h0087465

Besner, D., \& Stolz, J. A. (1999). What kind of attention modulates the Stroop effect? Psychonomic Bulletin \& Review, 6, 99-104.

Besner, D., Stolz, J. A., \& Boutilier, C. (1997). The Stroop effect and the myth of automaticity. Psychonomic Bulletin \& Review, 4, 221225 .

BOROWSKy, R., \& BESNER, D. (2006). Parallel distributed processing and lexical-semantic effects in visual word recognition: Are a few stages necessary? Psychological Review, 113, 181-195. doi:10.1037/0033 $-295 \times 113.1 .181$

Bouma, H. (1970). Interaction effects in parafoveal letter recognition. Nature, 226, 177-178.

Brown, T. L. (1996). Attentional selection and word processing in Stroop and word search tasks: The role of selection for action. American Journal of Psychology, 109, 265-286. doi:10.2307/1423276

Brown, T. L., Gore, C. L., \& CARR, T. H. (2002). Visual attention and word recognition in Stroop color naming: Is word recognition "automatic"? Journal of Experimental Psychology: General, 131, 220-240. doi:10.1037/0096-3445.131.2.220

Brown, T. L., Roos-Gilbert, L., \& Carr, T. H. (1995). Automaticity and word perception: Evidence from Stroop and Stroop dilution effects. Journal of Experimental Psychology: Learning, Memory, \& Cognition, 21, 1395-1411. doi:10.1037/0278-7393.21.6.1395

BrunN, J. L., \& FARAH, M. J. (1991). The relation between spatial attention and reading: Evidence from the neglect syndrome. Cognitive Neuropsychology, 8, 59-75. doi:10.1080/02643299108253367

CARRASCO, M. (2006). Covert attention increases contrast sensitivity: Psychophysical, neurophysiological, and neuroimaging studies. In S. Martinez-Conde, S. L. Macknik, L. M. Martinez, J. M. Alonso, \& P. U. Tse (Eds.), Visual perception Part 1: Fundamentals of vision. Law and mid-level processes in perception (pp. 33-70). Amsterdam: Elsevier.

Carrasco, M., \& McElree, B. (2001). Covert attention accelerates the rate of visual information processing. Proceedings of the National Academy of Sciences, 98, 5363-5367.

Chung, S. T. L. (2002). The effect of letter spacing on reading speed in central and peripheral vision. Investigative Ophthalmology \& Visual Science, 43, 1270-1276.

Coltheart, M., Rastle, K., Perry, C., Langdon, R., \& Ziegler, J. (2001). DRC: A dual route cascaded model of visual word recognition and reading aloud. Psychological Review, 108, 204-256. doi:10.1037/0033-295X.108.1.204

DAVIS, C. J. (2005). N-Watch: A program for deriving neighborhood size and other psycholinguistic statistics. Behavior Research Methods, 37, 65-70.

Ducrot, S., \& Grainger, J. (2007). Deployment of spatial attention to words in central and peripheral vision. Perception \& Psychophysics, 69, 578-590.
Facoetti, A., Zorzi, M., Cestnick, L., Lorusso, M. L., Molteni, M., PAGANONI, P., ET AL. (2006). The relationship between visuo-spatial attention and nonword reading in developmental dyslexia. Cognitive Neuropsychology, 23, 841-855. doi:10.1080/02643290500483090

Ferguson, R., Robidoux, S., \& Besner, D. (2009). Reading aloud: Evidence for contextual control over lexical activation. Journal of Experimental Psychology: Human Perception \& Performance, 35, 499-507. doi:10.1037/a0013162

Finkbeiner, M., \& Forster, K. I. (2008). Attention, intention, and domain-specific processing. Trends in Cognitive Sciences, 12, 59-64. doi:10.1016/j.tics.2007.11.003

Friedmann, N., \& Gvion, A. (2001). Letter position dyslexia. Cognitive Neuropsychology, 18, 673-696. doi:10.1080/02643290143000051

Hardyck, C., Chiarello, C., Dronkers, N. F., \& Simpson, G. V. (1985). Orienting attention within visual fields: How efficient is interhemispheric transfer? Journal of Experimental Psychology: Human Perception \& Performance, 11, 650-666. doi:10.1037/0096 $-1523.11 .5 .650$

KLEIN, R. M. (1994). Perceptual-motor expectancies interact with covert visual orienting under conditions of endogenous but not exogenous control. Canadian Journal of Experimental Psychology, 48, 167-181. doi:10.1037/1196-1961.48.2.167

Lachter, J., Forster, K. I., \& Ruthruff, E. (2004). Forty-five years after Broadbent (1958): Still no identification without attention. Psychological Review, 111, 880-913. doi:10.1037/0033 $-295 X .111 .4 .880$

LEVI, D. M. (2008). Crowding-An essential bottleneck for object recognition: A mini-review. Vision Research, 48, 635-654. doi:10.1016/j .visres.2007.12.009

Lindell, A. K., \& Nicholls, M. E. R. (2003). Attentional deployment in visual half-field tasks: The effect of cue position on word naming latency. Brain \& Cognition, 53, 273-277. doi:10.1016/S0278 $-2626(03) 00125-8$

Marzouki, Y., \& Grainger, J. (2008). Effects of prime and target eccentricity on masked repetition priming. Psychonomic Bulletin \& Review, 15, 141-148. doi:10.3758/PBR.15.1.141

Marzouki, Y., Grainger, J., \& Theeuwes, J. (2007). Exogenous spatial cueing modulates subliminal masked priming. Acta Psychologica, 126, 34-45. doi:10.1016/j.actpsy.2006.11.002

Marzouki, Y., Meeter, M., \& Grainger, J. (2008). Effects of primetarget spatial separation and attentional deployment on masked repetition priming. Perception \& Psychophysics, 70, 1393-1400. doi:10.3758/PP.70.7.1393

Masson, M. E. J., \& Loftus, G. R. (2003). Using confidence intervals for graphically based data interpretation. Canadian Journal of Experimental Psychology, 57, 203-220. doi:10.1037/h0087426

McCann, R. S., Folk, C. L., \& Johnston, J. C. (1992). The role of spatial attention in visual word processing. Journal of Experimental Psychology: Human Perception \& Performance, 18, 1015-1029. doi:10.1037/0096-1523.18.4.1015

Mozer, M. C. (1983). Letter migration in word perception. Journal of Experimental Psychology: Human Perception \& Performance, 9, 531546. doi:10.1037/0096-1523.9.4.531

Nicholls, M. E. R., \& Wood, A. G. (1998). The contribution of attention to the right visual field advantage for word recognition. Brain \& Cognition, 38, 339-357. doi:10.1006/brcg.1998.1052

Nicholls, M. E. R., Wood, A. G., \& HAYES, L. (2001). Cerebral asymmetries in the level of attention required for word recognition. Laterality, 6, 97-110. doi:10.1080/13576500042000089

O'Malley, S., \& Besner, D. (2008). Reading aloud: Qualitative differences in the relation between stimulus quality and word frequency as a function of context. Journal of Experimental Psychology: Learning, Memory, \& Cognition, 34, 1400-1411. doi:10.1037/a0013084

O’Malley, S., Reynolds, M. G., \& Besner, D. (2007). Qualitative differences between the joint effects of stimulus quality and word frequency in reading aloud and lexical decision: Extensions to Yap and Balota (2007). Journal of Experimental Psychology: Learning, Memory, \& Cognition, 33, 451-458. doi:10.1037/0278-7393.33.2.451

Ortells, J. J., Tudela, P., Noguera, C., \& Abad, M. J. F. (1998). Attentional orienting within visual field in a lexical decision task. Journal of Experimental Psychology: Human Perception \& Performance, 24, 1675-1689. doi:10.1037/0096-1523.24.6.1675

Perry, C., Zeigler, J. C., \& Zorzi, M. (2007). Nested incremen- 
tal modeling in the development of computational theories: The CDP + model of reading aloud. Psychological Review, 114, 273-315. doi:10.1037/0033-295X.114.2.273

Posner, M. I. (1980). Orienting of attention. Quarterly Journal of Experimental Psychology, 32, 3-25.

Posner, M. I., \& Peterson, S. E. (1990). The attention system of the human brain. Annual Review of Neuroscience, 13, 25-42.

Prinzmetal, W., Presti, D. E., \& Posner, M. I. (1986). Does attention affect visual feature integration? Journal of Experimental Psychology: Human Perception \& Performance, 12, 361-369. doi:10.1037/0096 $-1523.12 .3 .361$

Risko, E. F., Stolz, J. A., \& Besner, D. (2005). Basic processes in reading: Is visual word recognition obligatory? Psychonomic Bulletin \& Review, 12, 119-124.

Siéroff, E., \& Posner, M. I. (1988). Cuing spatial attention during processing of words and letter strings in normals. Cognitive Neuropsychology, 5, 451-472. doi:10.1080/02643298808253269

SNowden, R. J., Willey, J., \& MuIR J. L. (2001). Visuospatial attention: The role of target contrast and task difficulty when assessing the effects of cues. Perception, 30, 983-991. doi:10.1068/p3068

Spalek, T. M., \& Hammad, S. (2004). Supporting the attentional momentum view of IOR: Is attention biased to go right? Perception \& Psychophysics, 66, 219-233.

SternberG, S. (1969). The discovery of processing stages: Extensions of Donders' method. Acta Psychologica, 30, 276-315.

Stolz, J. A., \& McCann, R. S. (2000). Visual word recognition: Reattending to the role of spatial attention. Journal of Experimental Psychology: Human Perception \& Performance, 26, 1320-1331. doi:10.1037/0096-1523.26.4.1320

Stolz, J. A., \& Stevanovski, B. (2004). Interactive activation in visual word recognition: Constraints imposed by the joint effects of spatial attention and semantics. Journal of Experimental Psychology: Human Perception \& Performance, 30, 1064-1076. doi:10.1037/0096 $-1523.30 .6 .1064$

Treisman, A. [M.] (2006). How the deployment of attention determines what we see. Visual Cognition, 14, 411-443. doi:10.1080/ 13506280500195250

Treisman, A. M., \& Gelade, G. (1980). A feature-integration theory of attention. Cognitive Psychology, 12, 97-136. doi:10.1016/0010 $-0285(80) 90005-5$

Treisman, A. [M.], \& Souther, J. (1986). Illusory words: The roles of attention and of top-down constraints in conjoining letters to form words. Journal of Experimental Psychology: Human Perception \& Performance, 12, 3-17. doi:10.1037/0096-1523.12.1.3

Van Selst, M., \& Joliceur, P. (1994). A solution to the effect of sample size on outlier elimination. Quarterly Journal of Experimental Psychology, 47A, 631-650.

WoLFORD, G. (1975). Perturbation model for letter identification. Psychological Review, 82, 184-199. doi:10.1037/0033-295X.82.3.184

Wolford, G., \& ChAMBERs, L. (1983). Lateral masking as a function of spacing. Perception \& Psychophysics, 33, 129-138.

Yeshurun, Y., \& CARRasco, M. (1999). Spatial attention improves performance in spatial resolution tasks. Vision Research, 29, 293-306. doi:10.1016/S0042-6989(98)00114-x

Yu, D., Cheung, S.-H., Legge, G. E., \& Chung, S. T. L. (2007). Effect of letter spacing on visual span and reading speed. Journal of Vision, $7,1-10$.

(Manuscript received July 8, 2009;

revision accepted for publication January 27, 2010.) 